\title{
IMPLEMENTASI PERAN ASOSIASI CERDAS DAN BERBAKAT ISTIMEWA (CI+BI) NASIONAL DALAM PENINGKATAN MUTU LAYANAN PENDIDIKAN UNTUK SISWA CERDAS DAN BERBAKAT ISTIMEWA (CI+BI) INDONESIA
}

\author{
Intan Larange Arifin, Amril Muhammad, Siti Rochanah \\ larangearifin@gmail.com
}

\begin{abstract}
This research was conducted at Asosiasi CI+BI Nasional, which aims to determine the process of teamwork and communication is done Asosiasi CI+BI Nasional in improving the quality of educational services for gifted students and special intelligent Indonesia. This study was conducted in November 2015 and January 2016. The researchers used a qualitative approach and descriptive method. Data collected through interviews, observation, and documentation study. Source data from this study are: the general secretary of the Asosiasi CI+BI Nasional, chairman of the Asosiasi $C I+B I$ Wilayah, and some informants supporting, among others, the management areas of the Asosiasi CI+BI Nasional and school/madrasah service provider subsidiary CI+BI under the auspices of the Asosiasi CI+BI Nasional. Teamwork in Asosiasi CI+BI Nasional is done by those who want to work together to analyze needs and the resources available for cooperation with Asosiasi CI+BI Nasional. Then those who want to work together to contact Asosiasi CI+BI Nasional and did a deal related to the program to be implemented. Asosiasi CI+BI Nasional provides guidance to those who want to work together to reach areas of Asosiasi CI+BI Nasional in accordance with the needs and demands. Asosiasi CI+BI Nasional should help schools/madrasah service provider subsidiary CI+BI to look for students who have the potential of gifted special use technology optimally to notify information about the achievements of students $C I+B I$ by making connections between blogs Asosiasi CI+BI Nasional website owned by the school/madrasah service provider $C I+B I$ children under the auspices of Asosiasi $C I+B I$ Nasional.
\end{abstract}

Keywords: Teamwork, Communication, Asosiasi CI+BI Nasional.

\section{Pendahuluan}

Asosiasi penyelenggara, pengembang, dan pendukung pendidikan khusus untuk siswa cerdas/ berbakat istimewa ini, untuk selanjutnya disebut Asosiasi CI+BI Nasional dibentuk pada tanggal 11 Desember 2007 di Semarang untuk jangka waktu yang tidak ditentukan dan berkedudukan di Jakarta. Peran Asosiasi CI+BI Nasional adalah sebagai fasilitator, koordinator dan kolaborator pelaksanaan program yang dilaksanakan oleh pemerintah, masyarakat maupun anggota sesuai dengan kesepakatan bersama dengan mempertimbangkan potensi dan kemampuan masing-masing pihak terkait.

Menurut informasi yang diperoleh dari hasil grandtour, Asosiasi CI+BI Nasional menghimpun para penyelenggara program akselerasi di sekolah, para penyelenggara program keberbakatan di bidang seni dan olah raga. Bergabung juga para akademisi 
dari beberapa perguruan tinggi negeri ternama di Indonesia, antara lain: Universitas Indonesia, Universitas Negeri Jakarta, Institut Teknologi Bandung, Universitas Padjajaran, Universitas Sumatera Utara, Universitas Lampung, Universitas Andalas, Universitas Jambi, Universitas Bengkulu, Universitas Diponegoro, Universitas Gajah Mada, Universitas Airlangga, dan lain-lain. Alasan dari pelibatan perguruan tinggi negeri itu didasarkan hasil pengamatan. Hasil pengamatan tersebut menunjukkan bahwa PTN-PTN itulah yang menjadi tujuan dari lulusan program akselerasi. Harapannya dengan pelibatan itu, PTN yang bersangkutan bersedia menerima siswa lulusan akselerasi melalui jalur tanpa tes. Asosiasi CI+BI Nasional juga melibatkan masyarakat dan pemerintah untuk mendukung optimalisasi layanan pendidikan bagi siswa CI+BI.

Berangkat dari hal yang telah dipaparkan di atas, menarik perhatian peneliti untuk mengangkat fenomena tersebut. Peneliti tertarik mengusung tema peningkatan mutu layanan pendidikan yang meliputi kerja sama tim dan komunikasi. Penelitian dilakukan untuk mengetahui bagaimana peningkatan mutu layanan pendidikan secara nyata untuk siswa CI+BI Indonesia. Penelitian dilakukan di Asosiasi CI+BI Nasional. Adapun judul penelitian ini adalah 'Implementasi Peran Asosiasi Cerdas dan Berbakat Istimewa (CI+BI) Nasional dalam Peningkatan Mutu Layanan Pendidikan untuk Siswa Cerdas dan Berbakat Istimewa (CI+BI) Indonesia",

Berdasarkan latar belakang masalah tersebut, penelitian ini difokuskan pada 'Peningkatan Mutu Layanan Pendidikan', Sedangkan sub fokus penelitiannya adalah: kerja sama tim dan komunikasi di Asosiasi CI+BI Nasional. Permasalahan yang akan dibahas dalam penelitian ini adalah sebagai berikut: 1) Bagaimana Asosiasi CI+BI Nasional membangun kerja sama tim dengan sekolah/madrasah penyelenggara layanan anak CI+BI atau pihak terkait dalam upaya peningkatan mutu layanan pendidikan siswa cerdas dan berbakat istimewa Indonesia? 2) Bagaimana Asosiasi CI+BI Nasional membangun jalinan komunikasi dengan sekolah/madrasah penyelenggara layanan anak CI+BI atau pihak terkait dalam melakukan peningkatan mutu layanan pendidikan siswa cerdas dan berbakat istimewa Indonesia? 3) Bagaimana dampak dari kerja sama tim dan komunikasi yang dibangun oleh Asosiasi CI+BI Nasional?. Tujuan umum penelitian ini adalah untuk memperoleh data empiris dan untuk mengamati secara langsung kegiatan peningkatan mutu layanan pendidikan untuk siswa cerdas dan berbakat istimewa Indonesia oleh Asosiasi CI+BI Nasional.

\section{Kajian Teori}

Menurut Lewis (2009:13), quality is defined as 'the essential character of something, an inherent or distinguishing character, degree, or grade of excellence". Menurut Geiger yang dikutip oleh Neise (2009:1), quality is defined as the fulfillment of "the totality of characteristics of an entity (product) that beat on its ability to satisfy stated and implied needs; of the customer'. Menurut Sukirman (2003:149), mutu yaitu kesesuaian dengan persyaratan dan cocok untuk digunakan perlu diverifikasi melalui proses sistem jaminan mutu yang handal. Broto (2003:63) mengutip definisi mutu menurut International Organization for Standardization (ISO) di Eropa, ISO mendefinisikan mutu sebagai derajat dari keseluruhan karakteristik produk yang memenuhi tuntutan yang berasal dari sasaran penggunaan. WHO dalam Guidelines for Quality Assurance Programmes for Blood Transfusion Services yang dikutip oleh Cahyono (2008:356) memberikan definsi mutu sebagai pemberian pelayanan atau 
produk yang teratur dan dapat dipercaya serta sesuai dengan standar yang telah

Parasuraman, Zeithaml, dan Berry yang dikutip oleh Tjiptono (2000:69) menyatakan bahwa terdapat sepuluh faktor yang mempengaruhi kualitas jasa, yaitu reliability, responsiveness, competence, access, courtesy, communication, credibility, security, understanding/knowing the customer, dan tangibles. Menurut Tim Mitra Guru (2007:60), kerja sama adalah usaha bersama antarindividu atau kelompok untuk mencapai tujuan bersama. Menurut Poerwopoespito dan Utomo (2010:143), kerja sama bermakna bekerja bersama-sama, tidak ada yang berpangku tangan, semua anggota tim mempunyai beban, fungsi, dan tanggung jawab yang sama, dan hasilnya sesuai dengan jumlahnya. Menurut Tim Pengembang Ilmu Pendidikan FIP - UPI (2007:425), kerja sama adalah kemampuan untuk menyelesaikan tugas secara bersamasama. Menurut Dunn, Kathuria, dan Klotman (2013:84), definisi tim adalah a team is defined as two or more individuals with specified roles interacting adaptively, interdependently, and dynamically toward a shared and common goal. Definisi tim menurut Woodcock yang dikutip oleh Lishman (2007:326) yaitu, a team is a group of people who share common objectives and who need to work together to achieve them. Menurut Soegoto (2009:269), tim adalah suatu unit dari dua atau lebih orang-orang yang mengemban misi dan tanggung jawab kolektif ketika mereka bekerja sama untuk mencapai suatu tujuan bersama. Menurut Astuti (2008:88), tim merupakan kelompok dengan tujuan jelas yang terorganisir di mana setiap anggota dengan latar belakang keahlian, pengetahuan, personalitas, sejarah, dan fungsi yang berbeda melengkapi satu sama lain dengan tugas tertentu dalam memproduksi sesuatu di dalam tim.
Kerja sama tim menurut Brill yang dikutip oleh Hall (2005:40) yaitu, that work which is done by a group of people who possess individual expertise, who are responsible for making individual decisions, who hold a common purpose and who meet together to communicate, share and consolidate knowledge from which plans are made, future decisions are influenced, and action determined. Menurut Mackall (2004:18), teamwork is the process whereby a group of people pool their resources and skills to work together and achieve a common goal. Definisi kerja sama tim yang telah dikemukakan oleh Madura (2007:33), yaitu di mana sekelompok karyawan dengan beragam posisi pekerjaan bertanggung jawab untuk mencapai tujuan tertentu. Mackall (2004:11) mengatakan, putting the "Team" in Teamwork: Recognizing the importance of teams and don't forget the "work" in teamwork. Katzenbach dan Smith memberikan lima wawasan mengenai kesuksesan tim yang dikutip oleh Rippin (2002:52), yaitu: 1) There are six team basics: teams should be small, fewer than 12 people; team members should have complementary skills; the team should have a common purpose; there should be a common set of specific purpose goals; there should be a commonly agreed working approach; there must be mutual accountability, 2) A team approach should be chosen based on clearly defined performance outcomes. There must be a clear and compelling answer to the question, why do you need a team to achieve what you want to achieve?, 3) The team leader is seldom the primary determinant of team performance (having clear goals and a sense of purpose are far more likely to indicate success), 4) Most organizations have enormous untapped potential for using teams, dan 5) The organization needs a performance ethic or culture if it is to generate good teams. 
Menurut Rippin (2002:97), terdapat sepuluh poin untuk membuat kerja sama tim berfungsi di dalam sebuah tim, yaitu: 1) Decide if you really need a team, 2) Do you have the organizational culture to make teams work?, 3) How well do you communicate?, 4) Have you got very clear goals and objectives?, 5) What can you do about team spirit?, 6) Do you understand team dynamics?, 7) Do you play to strengths?, 8) Are you willing to get your hands dirty occasionally?, 9) Do you have clearly identified working norms?, 10) Do you treat people as you would like to be treated?.

Menurut Newman dan Summer Jr. State yang dikutip oleh Bisen (2009:2), communication is an exchange of facts, ideas, opinions or emotions by two or more persons. Bisen (2009:2) mengutip definisi komunikasi yang dikemukakan oleh Davis, yaitu the process of passing the information and understanding from one person to another. It is essentially a bridge of meaning between the people. By using the bridge a person can safely across the river of misunderstanding. Suprapto (2009:6) mengutip definisi komunikasi yang dikemukakan oleh Theodorson dan Thedorson, yaitu komunikasi adalah penyebaran, ide-ide sebagai sikap atau emosi dari seseorang kepada orang lain terutama melalui simbol-simbol. Wiryanto (2006:6) mengutip definisi menurut Trebnholm dan Jensen yang mendefiniskan komunikasi sebagai, a process by which a source transmits a message to a reciever through some channel". Sementara itu komunikasi menurut Ross yang dikutip oleh Wiryanto (2006:6), yaitu komunikasi didefinisikan sebagai suatu proses menyortir, memilih, dan mengirimkan simbol-simbol sedemikian rupa, sehingga membantu pendengar membangkitkan makna atau respons dari pikirannya yang serupa dengan yang dimaksudkan oleh sang komunikator.
Seeger, Sellnow, dan Ulmer (2003:65) mengemukakan communication is an ongoing process that enables organizations to monitor their environments before and during crisis, to understand and respond appropriately, to construct a consistent interpretation, and to resolve the crisis and reestablish order. Pace dan Faules (2005:24) mengemukakan tujuan utama dalam mempelajari komunikasi adalah memperbaiki organisasi. Menurut Tjiptono dan Diana (2003:170), komunikasi berfungsi untuk beberapa tujuan, yaitu untuk pengendalian, motivasi, ekspresi perasaan, dan informasi. menurut Uripni, Sujianto, dan Indrawati (2002:41) tujuan komunikasi efektif, yaitu memberi kemudahan dalam memahami pesan yang disampaikan antara pemberi dan penerima sehingga bahasa lebih jelas, lengkap, pengiriman dan umpan balik seimbang, dan melatih penggunaan bahasa nonverbal secara baik. Menurut Tjiptono (2000:39), bahwa bentuk ideal dari komunikasi memiliki beberapa ciri, yaitu: 1) Bisa menghasilkan efektifitas yang lebih besar, 2) Dapat menempatkan orang-orang pada posisi yang seharusnya (the right man on the right place), 3) Mampu meningkatkan keterlibatan, motivasi, dan komitmen setiap organisasi, 4) Dapat menghasilkan hubungan dan saling pengertian yang lebih baik antara atasan dan bawahan, antar rekan kerja, serta antara orang-orang dalam organisasi dan di luar organisasi, dan 5) Mampu membantu setiap individu dalam organisasi untuk memahami perlunya perubahan, yaitu berkenaan dengan bagaimana mengelola perubahan tersebut dan bagaimana mengurangi penolakan terhadap perubahan.

Menurut Depdiknas definisi anak gifted and talented yang dikutip oleh Hawadi (2011:34), yaitu mereka yang mempunyai taraf inteligensi atau IQ diatas 140 dan mereka yang oleh psikolog dan/atau guru diidentifikasikan sebagai peserta didik yang 
telah mencapai prestasi yang memuaskan, dan memiliki kemampuan intelektual umum yang berfungsi pada taraf cerdas, dan keterikatan terhadap tugas yang tergolong baik serta kreativitas yang memadai. Menurut Hawadi (2011:34) anak berbakat adalah mereka yang diidetifikasikan oleh orang-orang yang berkualifikasi profesional memiliki kemampuan luar biasa dan mampu berprestasi tinggi. Mereka yang memiliki tipe accelerated, yaitu lebih mampu menguasai dan mengintegrasikan bahan-bahan pelajaran yang kompleks. Mereka memiliki kemampuan untuk belajar dan mengingat kembali sejumlah besar informasi dengan cepat. Berdasarkan definisi yang dikutip oleh Gunarsa dan Yulia Singgih (2004:83), Renzulli et al., mengemukakan giftedness consists of an interaction among three basic clusters of human traits-these clusters being above average general abilities, high levels of task commitment and high levels of creativity. Sementara itu definisi anak gifted and talented menurut Webb et al. (2007:1), children like these are thinking and behaving in ways that are advanced and different when they are compared with other children their same age. We call these children "gifted," "talented," or "creative". Definisi anak gifted and talented yang digambarkan The Texas State Plan for the Education of Gifted/Talented Students (1996) yang dikutip oleh Tucker (2009:1), yaitu giftedness as ' child or youth who performs at or shows the potential for performing at a remarkably high level of accomplishment when compared to others of the same age, experience, or environment.

Compton (2011:8) mengutip pernyataan yang dikemukakan oleh Clark yaitu intense curiosity, frequent and sophisticated questions, an accelerated pace of thought and learning, complex thinking, often connecting seemingly disparate ideas, persistence in pursuing interests, and early development of language and mathematical skills. Menurut Renzulli yang dikutip oleh Hawadi (2011:56), keberbakatan merupakan hasil perpaduan dari kemampuan di atas ratarata, kreativitas, dan komitmen pada tugas. Hawadi (2011:64) mengutip pernyataan Amabile yang menyatakan terdapat empat penghambat kreativitas, yaitu evaluasi, hadiah, persaingan (kompetisi), dan lingkungan yang membatasi. Menurut Clark yang dikutip oleh Compton (2011:7), from an overwhelming body of research, we must conclude that the development of intelligence includes both nature and nurture. Ragam kecerdasan menurut Gardner yang dikutip oleh Compton (2011:14) yaitu, linguistic, logical-mathematical, spatial, musical, bodily-kinesthetic, interpersonal, intrapersonal, and naturalist.

\section{Metode Penelitian}

Penelitian ini menggunakan pendekatan kualitatif, Sedangkan metode yang digunakan adalah metode deskriptif. Penelitian ini dilakukan di Asosiasi CI+BI Nasional. Penelitian menggunakan dua jenis sumber data yaitu data primer dan data sekunder. Data primer dalam penelitian ini menggunakan purposive sampling dan snowball sampling. Dalam penelitian, pihak yang dijadikan informan yaitu pengurus Asosiasi CI+BI Nasional, pengurus Asosiasi CI+BI Wilayah, kepala sekolah penyelenggara layanan anak $\mathrm{CI}+\mathrm{BI}$, koordinator program layanan anak $\mathrm{CI}+\mathrm{BI}$, dan guru program layanan anak $\mathrm{CI}+\mathrm{BI}$. Sedangkan data sekunder yang diperoleh berupa dokumen yang memuat visi dan misi Asosiasi CI+BI Nasional. Selain itu, peneliti juga mengumpulkan dokumen terkait profil, struktur organisasi, dan program Asosiasi CI+BI Nasional.

Teknik pengumpulan data yang digunakan yaitu observasi non partisipatif, wawancara 
mendalam, dan analisis dokumentasi. Dalam analisis data, pertama-tama peneliti melakukan pengumpulan data. Kedua, peneliti malakukan reduksi data dengan menyederhanakan data yang terkumpul. Ketiga, peneliti menyajikan data dilakukan dengan mendeskripsikan informasi yang didapat dalam bentuk teks naratif, tabel, dan gambar. Keempat, peneliti membuat kesimpulan-kesimpulan/verifikasi.

\section{Hasil Penelitian}

Hasil penelitian yang berkaitan dengan kerja sama tim yaitu a) Asosiasi CI+BI Nasional melibat unsur sekolah penyelenggara, perguruan tinggi pendamping, dan unsur pendukung dalam bekerja sama. Unsur pendukung yang dimaksud adalah pemerintah dan tokoh masyarakat, b) Antara Asosiasi CI+BI Nasional dengan sekolah/madrasah penyelenggara layanan anak CI+BI setidaknya memiliki tiga bentuk kerja sama. Pertama, bekerja sama dalam penyusunan pedoman penyelenggaraan program akselerasi. Kedua, bekerja sama dalam penyusunan buku bahan ajar untuk program akselerasi. Ketiga, bekerja sama dalam pemberian pelatihan peningkatan kompetensi guru program akselerasi, c) Pengurus Asosiasi CI+BI Nasional menjadi pemateri dalam workshop atau pelatihan terkait anak CI+BI sesuai kepakarannya masing-masing, d) Asosiasi CI+BI Nasional memiliki bidang-bidang yang mewakili karakteristik siswa CI+BI. Terdapat bidang MIPA, psikologi, pendidikan, seni, olahraga, ICT, lembaga pendidikan CI, dan lembaga pendidikan $\mathrm{BI}$.

Hasil penelitian yang berkaitan dengan komunikasi yaitu a) Asosiasi CI+BI Nasional banyak memberikan informasi-informasi terkait anak CI+BI. Mulai dari informasi mengenai karakteristik anak $\mathrm{CI}+\mathrm{BI}$ sampai dengan informasi mengenai isu terkait program CI+BI dan peraturan baru dari pemerintah khususnya Pendidikan Khusus dan Layanan Khusus, b) Asosiasi CI+BI Nasional berkomunikasi melalui email, telfon, short message service (SMS), Whatsapp Massenger, dan tatap muka. Asosiasi CI+BI Nasional juga memanfaatkan dunia maya seperti facebook, twitter blog sebagai media untuk berkomunikasi, c) Asosiasi CI+BI Nasional tidak membatasi siapa saja untuk mengakses informasi mengenai siswa $\mathrm{CI}+\mathrm{BI}$ dalam akun jejaring milik Asosiasi CI+BI Nasional. Komunikasi yang dibangun Asosiasi CI+BI Nasional bersifat egaliter atau setara bagi siapa pun yang mempunyai kepentingan.

\section{Pembahasan}

Jaringan kerja sama Asosiasi CI+BI Nasional sejalan dengan teori yang dikemukakan oleh Astuti, yaitu, "Tim merupakan kelompok dengan tujuan jelas yang terorganisir di mana setiap anggota dengan latar belakang keahlian, pengetahuan, personalitas, sejarah, dan fungsi yang berbeda melengkapi satu sama lain dengan tugas tertentu dalam memproduksi sesuatu di dalam tim. Asosiasi CI+BI Nasional menyadari bahwa kerja sama yang terjalin ini membutuhkan semua pihak untuk bekerja sama. Hal ini sejalan dengan teori yang dikemukakan oleh Dunn, Kathuria, dan Klotman, "'a team is defined as two or more individuals with specified roles interacting adaptively, interdependently, and dynamically toward a shared and common goal'. Tahapan yang dilakukan sekolah/madrasah penyelenggara layanan anak CI+BI untuk dapat bekerja sama dengan Asosiasi CI+BI Nasional adalah melakukan analisis kebutuhan. Hal ini sejalan dengan teori yang dikemukakan oleh Addesso, "also has a checklist of what makes a team. A team, she argues: Sets goals, analyzes and solves problems, implements the solutions, andfeels responsible for its output. 
Asosiasi CI+BI Nasional berusaha mencapai keefektifan kerja sama dengan menyepakati kegiatan yang ingin dilaksanakan oleh sekolah/madrasah. Hal ini sejalan dengan teori yang dikemukakan oleh Tjiptono dan Diana, yaitu karakteristik dari tim adalah adanya kesepakatan terhadap misi tim, semua anggota mentaati peraturan tim yang berlaku, ada pembagian tanggung jawab dan wewenang yang adil, serta anggota tim beradaptasi terhadap perubahan. Dalam rangka pencapaian tujuan, Asosiasi $\mathrm{CI}+\mathrm{BI}$ Nasional melakukan beberapa strategi. Hal ini sejalan dengan strategi yang dikemukakan King yang dikutip oleh Tjiptono, yaitu saling ketergantungan, perluasan tugas, penjajaran (alignment), bahasa yang umum, kepercayaan/respek, kepemimpinan / keanakbuahan yang dibagi rata, keterampilan pemecahan masalah, keterampilan mengenai konfrontasi/konflik, penilaian/tindakan, dan perayaan.

Group dalam facebook Asosiasi CI+BI Nasional merupakan wadah berkomunikasi dengan masyarakat. Peran serta masyarakat dalam bentuk pemikiran, saran, dan aktivitas. Hal ini sejalan dengan teori yang dikemukakan oleh Newman dan Summer Jr. State, 'Communication is an exchange of facts, ideas, opinions or emotions by two or more persons'.' Asosiasi CI+BI Nasional memanfaatkan blog, twitter, facebook, email, telfon, SMS, WA, dan tatap muka sebagai media komunikasi. Hal ini sejalan dengan teori yang dikemukakan oleh Trebnholm dan Jensen yang mendefiniskan komunikasi sebagai, "A proces By whuch a source transmits a message to a reciever through some channel". Asosiasi CI+BI Nasional menjembatani informasi-informasi terbaru terkait pendidikan siswa $\mathrm{CI}+\mathrm{BI}$ yang berasal dari pemerintah ke masyarakat luas. Hal ini sejalan dengan teori yang dikemukakan oleh Davis, yaitu, "The process of passing the information and understanding from one person to another. It is essentially a bridge of meaning between the people. By using the bridge a person can safely across the river of misunderstanding' '. Hal tersebut juga sejalan dengan teori yang dikemukakan oleh Ross, yaitu komunikasi didefinisikan sebagai suatu proses menyortir, memilih, dan mengirimkan simbol-simbol sedemikian rupa, sehingga membantu pendengar membangkitkan makna atau respons dari pikirannya yang serupa dengan yang dimaksudkan oleh sang komunikator.

Komunikasi efektif yang dilakukan Asosiasi $\mathrm{CI}+\mathrm{BI}$ Nasional adalah dengan menggunakan bahasa yang tepat dan mudah dimengerti. Hal ini sejalan dengan teori yang dikemukakan oleh Ristica, et.al, sebagai berikut: 1) Sebagai pengirim: menggunakan bahasa yang tepat, empati, mempertajam persepsi, mengendalikan bentuk tanggapan dengan tepat, bersedia menerima umpan balik positif maupun negatif, mengembangkan kredibilitas diri sehingga dapat dipercaya, dan mempertahankan hubungan baik dengan penerima, 2) Sebagai penerima: meningkatkan kemampuan untuk mendengarkan, waspada terhadap prasangka dan bias, mengembangkan kecakapan untuk bertanya, mengembangkan kecakapan menyampaikan umpan balik secara konstruktif, berusaha berfikir kreatif terhadap pesan yang diterima, bersikap terbuka tetapi kritis, benar-benar mengerti pesan komunikasi, dan saat mengambil keputusan sadar akan tujuannya, 3) Keefektifan komunikasi antar pribadi dipengaruhi oleh faktor-faktor berikut: keterbukaan, empati, mendukung, positif, keseimbangan, percaya diri, kesegaran, manajemen interaksi, mengungkapkan, dan berorientasi pada orang lain.

Ketika terdapat tanggapan yang kurang berkaitan dengan siswa $\mathrm{CI}+\mathrm{BI}$, maka Asosiasi CI+BI Nasional mengendalikan 
tanggapan tersebut. Pengendalian dilakukan dengan memberikan respon yang tidak menyinggung namun tetap jelas terhadap tanggapan tersebut. Hal tersebut juga didasarkan pada keinginan untuk mempertahankan hubungan baik dengan penerima pesan. Hal ini juga sejalan dengan teori yang dikemukakan Tjiptono dan Diana, komunikasi berfungsi untuk beberapa tujuan, yaitu untuk pengendalian, motivasi, ekspresi perasaan, dan informasi.

Asosiasi CI+BI Nasional meminta koordinator kelas akselerasi memberikan laporan terkait siswa CI+BI. Hal ini sejalan dengan tujuan komunikasi efektif yang dikemukakan Uripni, Sujianto, dan Indrawati yaitu memberi kemudahan dalam memahami pesan yang disampaikan antara pemberi dan penerima sehingga bahasa lebih jelas, lengkap, pengiriman dan umpan balik seimbang, dan melatih penggunaan bahasa nonverbal secara baik. Berdasarkan informasi dari laporan yang diperoleh, pengurus Asosiasi CI+BI Nasional akan merumuskan program-program selanjutnya. Hal ini sejalan dengan teori yang dikemukakan oleh Seeger, Sellnow, dan Ulmer, "Communication is an ongoing process that enables organizations to monitor their environments before and during crisis, to understand and respond appropriately, to construct a consistent interpretation, and to resolve the crisis and reestablish order." Program lanjutan ini dirancang dengan tujuan untuk memperbaiki dan menyempurnakan program sebelumnya. Hal ini sejalan dengan tujuan yang dikemukakan oleh Pace dan Faules yang menyatakan bahwa Tujuan utama dalam mempelajari komunikasi adalah memperbaiki organisasi.

Kerja sama dan komunikasi yang terjalin antara Asosiasi CI+BI Nasional dengan sekolah/madrasah penyelenggara layanan anak CI+BI sejalan dengan teori yang dikemukakan oleh Brill mendefinisikan kerja sama tim sebagai, "That work which is done by a group of people who possess individual expertise, who are responsible for making individual decisions, who hold a common purpose and who meet together to communicate, share and consolidate knowledge from which plans are made, future decisions are influenced, and action determined."

\section{Kesimpulan}

1. Proses kerja sama yang dilakukan adalah a) Sekolah/madrasah penyelenggara layanan anak $\mathrm{CI}+\mathrm{BI}$ melakukan analisis kebutuhan untuk dapat bekerja sama dengan Asosiasi CI+BI Nasional;

Sekolah/madrasah menyampaikan permohonan pendampingan kepada Asosiasi CI+BI Nasional; c) Asosiasi memberikan arahan agar sekolah/madrasah menghubungi bidang-bidang Asosiasi CI+BI Nasional akan melakukan pendampingan sesuai dengan kebutuhan atau permintaan; d) Pengurus Asosiasi CI+BI Nasional menjadi pemateri dalam kegiatan seperti workshop atau pelatihan dan juga dapat membantu menyusun pedoman penyelenggaraan kelas akselerasi, desain program, materi, metodologi pembelajaran, dan sistem penilaian untuk siswa $\mathrm{CI}+\mathrm{BI}$;

2. Proses komunikasi yang terjalin adalah a) Mengetahui jenis pesan yang ingin disampaikan; b) Menentukan media yang ingin digunakan untuk berkomunikasi dengan Asosiasi CI+BI Nasional; c) Mempertimbangkan waktu yang digunakan untuk menghubungi Asosiasi CI+BI Nasional; d) 
Menyampaikan kegiatan yang ingin dilaksanakan dalam kerja sama dengan Asosiasi CI+BI Nasional; d) Kegiatan yang disepakati terlaksana dengan baik;

\section{Saran}

1. Kepada Asosiasi CI+BI Nasional, saran yang dapat diberikan dalam upaya peningkatan mutu layanan pendidikan untuk siswa CI+BI adalah sebaiknya Asosiasi CI+BI Nasional membuat form penilaian untuk kinerja pengurus Asosiasi CI+BI Nasional. Selain itu, sebaiknya pengurus Asosiasi $\mathrm{CI}+\mathrm{BI}$ Nasional memilih tiga pengurus terbaik selama satu periode kepengurusan. Dalam hal komunikasi sebaiknya pengelola blog Asosiasi CI+BI Nasional setidaknya mem-posting informasi mengenai anak CI+BI dalam dua atau tiga minggu sekali. Sebaiknya Asosiasi CI+BI Nasional juga mengoptimalkan pemanfaatan teknologi untuk menunjukkan prestasi siswa $\mathrm{CI}+\mathrm{BI}$ di sekolah/madrasah yang berada dalam naungan Asosiasi CI+BI Nasional.

2. Kepada sekolah/madrasah penyelenggara layanan anak $\mathrm{CI}+\mathrm{BI}$ yang Berada dalam Naungan Asosiasi CI+BI Nasional, sebaiknya sekolah/madrasah ikut membantu dengan memberikan informasi mengenai kondisi program, guru, dan siswa CI+BI di sekolah/madrasah secara intens kepada Asosiasi CI+BI Nasional. Sebaiknya sekolah/madrasah ikut mensosialisasikan kepada orang tua siswa $\mathrm{CI}+\mathrm{BI}$ mengenai jejaring dunia maya yang dimiliki oleh Asosiasi CI+BI Nasional. Sekolah/madrasah sebaiknya memanfaatkan secara optimal data-data yang berada di dalam jejaring dunia maya milik Asosiasi CI+BI Nasional.

3. Kepada peneliti lain, saran yang dapat diberikan bagi peneliti lain yaitu hendaknya lebih kreatif dalam mengembangkan kajian penelitian dengan menggunakan metode dan teknik penelitian yang berbeda dan variatif agar informasi yang diperoleh lebih akurat dan lengkap dalam rangka memperkaya kajian peningkatan mutu layanan di dunia pendidikan.

\section{Daftar Pustaka}

Anonim. (2011). Parenting Gifted Children. Lacy Compton (Eds.). United States of America: National Association for Gifted Children.

Astuti, Ponny Retno. (2008). Meredam Bullying: 3 Cara Efektif Mengatasi K.P.A. Jakarta: Grasindo.

Bisen, Vikram. (2009). Business

Communication. New Delhi: New Age International Ltd.

Broto, Wisnu. (2003). Mangga : Budidaya, Pasca Panen, dan Tata Niaganya. Jakarta: AgroMedia Pustaka.

Cahyono, J. B. Suharjo. B. (2008). Membangun Budaya Keselamatan Pasien dalam Praktik Kedokteran. Yogyakarta: Kanisius.

Danim, Sudarwan. (2002). Menjadi Peneliti Kualitatif. Bandung: CV. Pustaka Setia.

Dunn, Andrew. Kathuria, Navneet. dan Klotman, Paul. (2013). Essentials of 
Hospital Medicine A Partical Guide for Clinicians. Singapore: World Scientific Publishing Co. Pte. Ltd.

Endraswara, Suwardi. (2006). Metode, Teori, Teknik Penelitian Kebudayaan: Ideologi Epistemologi, dan Aplikasi. Yogyakarta: Pustaka Widyatama.

Gunarsa, Singgih D. Gunarsa, Yulia Singgih D. (2004). Psikologi Praktis : Anak, Remaja dan Keluarga. Jakarta: Gunung Mulia

Hall, Linda McGillis. (2005). Quality Work Environments for Nurse and Patient Safety. United States of America: Jones and Bartlett Publishers, Inc.

Hamdi, Asep Saepul. Bahruddin, E. (2014). Metode Penelitian Kuantitatif Aplikasi dalam Pendidikan. Yogyakarta: Deepublish.

Hawadi, Reni Akbar. (2011). Akselerasi: AZ Informasi Program Percepatan Belajar dan Anak Berbakat Intelektual. Jakarta: Gramedia Pustaka Utama.

Lewis, William E. (2009). Software Testing and Continuous Quality Improvement. United States of America: Taylor \& Francis Group, LLC.

Lishman, Joyce. (2007). Handbook for Practice Learning in Social Work and Social Care. London: Jessica Kingsley Publishers.

Mackall, Dandi Daley. (2004). Careers Skills Library: Teamwork Skills, Second Edition. United States of America: Facts On File, Inc.

Madura, Jeff. (2007). Introduction to Business. Jakarta: Salemba Empat.
Mahmud, Muh. Araba'in. (2015). Gender dan Kehutanan Masyarakat. Yogyakarta: Deepublish.

Neise, Patrick. (2009). Forschungsberichte. Munchen: erbert Utz Verlag GmbH.

Nursalam. (2008). Konsep dan Penerapan Metodologi Penelitian Ilmu Keperawatan. Jakarta: Salemba Medika.

Oktavia, Nova. (2015). Sistematika Penulisan Karya Ilmiah. Yogyakarta: Deepublish.

Pace, R. Wayne. Faules, Don F. (2005). Komunikasi Organisasi: Strategi Meningkatkan Kinerja Perusahaan. Diterjemahkan oleh Deddy Mulyana. Bandung: PT Remaja Rosdakarya.

Pawito. (2008). Penelitian Komunikasi Kualitatif. Yogyakarta: LKiS.

Poerwopoespito, Oerip S. Utomo, T. A. Tatag. (2010). Menggugah Mentalitas Profesional \& Pengusaha Indonesia. Jakarta: Grasindo.

Rippin, Ann. (2002). Teamworking. United Kingdom: Capstone Publishing.

Ristica, Octa Dwienda. dkk. (2015). Cara Mudah Menjadi Bidan yang Komunikatif. Yogyakarta: Deepublish.

Seeger, Matthew Wayne. Sellnow, Timothy L. dan Ulmer, Robert R. (2003).

Communication and Organizational Crisis. United States of America: Praeger Publishers.

Soegoto, Eddy Soeryanto. (2009).

Enterpreneurship Menjadi Pebisnis Ulung. Jakarta: Kompas Gramedia. 
Sudarma, Momon. (2008). Sosiologi untuk Kesehatan. Jakarta: Salemba Medika.

Sukirman, Silvia. (2003). Beton Aspal Campuran Panas. Jakarta: Granit.

Suparno, Paul. (2007). Riset Tindakan untuk Pendidik. Jakarta: Grasindo

Suprapto, Tommy. (2009). Pengantar Teori dan Manajemen Komunikasi. Yogyakarta: Media Pressindo.

Tim Mitra Guru. (2007). Ilmu Pengetahuan Sosial: Sosiologi untuk SMP dan MTs Kelas VII Standar Isi 2006. Jakarta: Erlangga.

Tim Pengembang Ilmu Pendidikan FIP UPI. (2007). Ilmu dan Aplikasi Pendidikan. Bandung: PT Imperial Bhakti Utama.

Tjiptono, Fandy. Diana, Anastasia. (2003). Total Quality Management. Yogyakarta: Andi.

Tjiptono, Fandy. (2000). Manajemen Jasa. Yogyakarta: Andi.

Tjiptono, Fandy. (2000). Prinsip-prinsip Total Quality Service. Yogyakarta: Andi.
Tucker, Tammy Newman. (2009). Searching for Hidden Treasure the Identification of Underrepresented Gifted and Talented Students. Texas: ProQuest LLC.

Uripni, Christina Lia. Sujianto, Untung. dan Indrawati, Tatik. (2002). Komunikasi Kebidanan. Jakarta: Penerbit Buku Kedokteran EGC.

Webb, James T. et al. (2007). A Parent's Guide to Gifted Children. United States of America: Great Potential Press, Inc.

Wiryanto. (2006). Pengantar Ilmu Komunikasi. Jakarta: Grasindo.

Asosiasi CI+BI Nasional, Profil Asosiasi CI+BI Nasional. diakses pada tanggal 28 September 2015 pukul 10.47 WIB.

https://asosiasicibinasional.wordpress.com/s alam-cibi/about/

Universitas Negeri Yogyakarta, BAB III Metode Penelitian. diakses pada tanggal 20 Oktober 2015 pukul 02.14 WIB. http://eprints.uny.ac.id/9718/3/Bab\%203\%2 0-07104241010.pdf 